\begin{tabular}{|l|l|l|l|l|l|}
\hline J. Tek. Ling & Vol. 13 & No. 2 & Hal. $167-177$ & Jakarta, Mei 2012 & ISSN 1441-318X \\
\hline
\end{tabular}

\title{
ANALISIS KIMIA LIMBAH B3 UNTUK MENENTUKAN EFISIENSI PENGHANCURAN DALAM UJI BAKAR DI INSINERATOR
}

\author{
Kardono \\ Pusat Teknologi Lingkungan, Badan Pengkajian dan Penerapan Teknologi
}

\begin{abstract}
Abstrak
Salah satu cara efektif mengurangi limbah bahan berbahaya dan beracun (B3) yaitu dengan membakarnya dalam insinerator. Berbagai keuntungan pembakaran limbah dalam insinerator mendorong usaha memanfaatkannya untuk menghacurkan limbah B3 di Indonesia. Keputusan Menteri Lingkungan Hidup (Men-LH) no. 18/2009 memungkinkan orang mendapat ijin pengolahan limbah B3 melalui insinerator, tetapi berdasarkan Keputusan Kepala BAPEDAL No.: Kep-03/1995, mereka harus memenuhi persyaratan efisiensi penghancuran (DRE) sebesar 99,99\% atau lebih, dan juga persyaratan lainnya. Pembuktian efisiensi penghancuran dilakukan melalui kegiatan uji bakar (TBT). Sebelum uji bakar dilakukan, analisis kimia limbah harus dilakukan di laboratorium. Senyawa yang paling sulit terbakar dalam uji bakar dapat dipilih berdasarkan nilai bakar senyawa dari hasil analisis tersebut. Dalam penelitian ini analisis kimia dari tiga jenis limbah B3, sarung tangan terkontaminasi, lumpur dari instalasi pengolahan limbah dan limbah infeksius rumah sakit, telah dilakukan. Hidrokarbon organic utama $(\mathrm{POHC})$ yang dianalisis dari ketiga limbah ini adalah 1.1 Dichlorethylene, 1.1.1 Trichloroethylene dan Tetrachloroethylene dengan konsentrasi masing-masing sebesar $1.411,0.311$, dan $0.166 \mathrm{mg} / \mathrm{kg}$. Hasil perhitungan indek panas pembakarannya masing-masing adalah $38.45,57.78$ and 84.20 . Jadi, Tetrachloroethylene merupakan $\mathrm{POHC}$ yang paling sulit terbakar sehingga terpilih sebagai wakil semua $\mathrm{POHC}$ yang mungkin terkandung dalam limbah B3 tersebut dalam uji bakar. Sampling untuk emisi Tetrachloroethylene menggunakan metode baku US EPA No. 30. Dalam uji bakar disarankan untuk mengukur emisi partikulat, logam-logam berat, asam khlorida $(\mathrm{HCl})$ dan gas-gas emisi lainnya ((O2, $\mathrm{CO}, \mathrm{CO} 2$, laju alir gas emisi, kadar air gas) dengan metode sampling baku. Data-data ini dapat digunakan untuk melakukan koreksi dan membantu dalam perhitungan hasil sampling.
\end{abstract}

Kata Kunci: Limbah Bahan Berbahaya dan Beracun (B3), Uji Bakar (TBT), Efisiensi Penghancuran (DRE), Indek Panas Pembakaran (I), Senyawa Hidrokarbon Organic Utama (POHC).

\begin{abstract}
One effective way to reduce industrial hazardous wastes is to burn them in the incinerators. A variety of advantages of the waste incineration has caused businesses on employing incinerator for hazardous waste destruction in Indonesia. Regulation of the State Minister for the Environment No. 18/2009 allows business people to have licenses to treat hazardous waste through incinerator but according to the Decree of the Head of the Environmental Management Agency (BAPEDAL) No.: Kep-03/1995 they must meet requirement of achieving $99.99 \%$ or more destruction removal efficiency (DRE) and other requirements. A demonstration of achieving DRE is done through a trial burn test (TBT).
\end{abstract}


Prior to TBT, the chemical analyses of the wastes need to be done in the laboratory. The most difficult compund to be burned in the TBT can be selected based on concentrations and heating values of those results. In this research, chemical analyses of three kinds of waste, contaminated gloves, wasterwater treatment sludge, and infectious medical wastes, have been carried out. The principal organic hydrocarbons (POHCs) analyzed are found to be 1.1 Dichlorethylene, 1.1.1 Trichloroethylene and Tetrachloroethylene with the respective average concentrations of $1.411,0.311$, and $0.166 \mathrm{mg} / \mathrm{kg}$. The respective calculated heat of combustion indexs are 38.45, 57.78 and 84.20. Thus, Tetrachloroethylene is a POHC that is most difficult to be burned and therefore it is chosen to be a representation of all POHCs of the wastes for TBT. Sampling method of Tetrachloroethylene emission uses US EPA Method 30 -Volatile Organic Sampling Train (VOST). During TBT it is also suggested to measure particulate, metals, chloride acid $(\mathrm{HCl})$, and other emitted gases (O2, $\mathrm{CO}, \mathrm{CO} 2$, gaseous emission rate, gas water content) with standard sampling methods. These data could be use to standarize and support the calculationn of the sampling results.

Key words: Hazardous wastes, Trial Burn Test (TBT), Destruction Removal Efficiency (DRE), Heat of Combustion Index (I), Principal Organic Hydrocarbons (POHCS).

\section{PENDAHULUAN}

\subsection{Latar Belakang}

Dengan berkembangnya industri sekarang ini memicu adanya peningkatan jumlah limbah dalam masyarakat. Kemampuan tanah dan udara untuk menyerap limbah-limbah ini sangatlah terbatas. Sungaitercemar, langit yang gelap dan tanah-tanah tertutup limbah adalah endemik terhadap dunia yang padat dengan industri.

Salah satu cara yang dianggap paling efektif untuk mengurangi limbah-limbah tersebut yakni dengan melakukan program pengurangan limbah di sumbernya. Di dalam area industri berarti adanya modifikasi proses atau penerapan pasar baru untuk pengolahan limbah.

Ketika industri berusaha sekuat tenaga melakukan pengurangan limbah, lokasi disposal limbah yang sebelumnya menjadi alternatif utama telah tertutup, khususnya untuk limbah bahan berbahaya dan beracun (B3). Insinerasi menjadi cara yang lebih menarik sebagai alternatif metode disposal. Berbagai keuntungan penggunaan insinerator ${ }^{1}$ untuk menghancurkan limbah
B3 menyebabkan banyak pelaku usaha mengajukan ijin pengolahan limbah B3 dengan insinerasi di Indonesia.

Peraturan Menteri Negara Lingkungan Hidup (Men-LH) Nomor 18 Tahun 2009 tentang Tata Cara Perizinan Pengelolaan Limbah Bahan Berbahaya dan Beracun (B3) ${ }^{2}$ mewajibkan pemilik atau pengolah limbah B3 dengan insinerator untuk melakukan uji bakar agar mendapatkan ijin pengoperasian insinerator tersebut. Selanjutnya Keputusan Kepala Badan Pengendalian Dampak Lingkungan (BAPEDAL) Nomor: Kep-03 Tahun1995 mensyaratkan limbah B3 yang akan dihancurkan melalui insinerator harus mencapai efisiensi penghancuran 99,99\% atau lebih ${ }^{3}$. Dalam rangka mendapatkan ijin pengoperasian insinerator tersebut, pemilik atau operator harus mendemonstrasikan bahwa insinerator mereka dapat beroperasi pada efisiensi penghancuran yang ditetapkan dan sering disebut dengan destruction and removal efficiency (DRE) $)^{3}$. Demonstrasi penunjukan ini sering dilakukan melalui uji bakar atau trial burn test (TBT) ${ }^{2,4,5}$.

Sebelum uji bakar dilaksanakan, pemilik atau operator harus melakukan analisis limbah B3 yang akan dibakar dalam insinerator dan menentukan jenis dan kadar 
senyawa kimianya merujuk pada Lampiran PP no 18/19996 atau lebih rinci dapat dilihat pada Appendix VIII, Resource Conservation and Recovery Act, RCCA, US-EPA7. Hasil analisis ini memungkinkan pemilik atau operator menentukan principal organic hazardous constituents (POHCs) dan parameter lainnya dalam limbah ${ }^{1,4,6,7}$. $\mathrm{POHC}$ ini biasanya senyawa dalam limbah yang sulit terbakar, bersifat toksik dan ditemukan dalam konsentrasi yang tinggi.

Dalam uji bakar nantinya, POHC ini dilakukan sampling emisi dan analisis laboratorium untuk menentukan apakah incinerator memenuhi DRE untuk senyawasenyawa POHC yang disyaratkan ${ }^{2,4,8}$. Kemudian, pemilik atau operator menyiapkan aplikasi ijin pembakaran yang disampaikan ke pemerintah $(\mathrm{KLH})^{2}$. Bagian dari perijinan, pemilik atau operator akan memberikan informasi hasil analisis limbah, mengusulkan $\mathrm{POHC}$ tertentu sebagai wakil keseluruhan senyawa yang ada untuk dilakukan TBT, dan menentukan metode sampling dan analisisnya yang akan digunakan sebagai acuan dalam mendapatkan data selama uji bakar nantinya. Bagian dari aplikasi perijinan disebut rencana uji pembakaran (trial burn plan) ${ }^{1,4}$

\subsection{Tujuan}

Tujuan dari penelitian ini adalah melakukan analisis kimia limbah B3 untuk menentukan wakil $\mathrm{POHC}$ yang siap untuk dilakukan uji bakar dalam menghitung besarnya DRE serta menyiapkan metode sampling dan analisis yang akan digunakan untuk mengukur emisi dalam rangka membuat rencana uji bakar (TBT) dalam insinerator.

\section{METODOLOGI}

\subsection{Persiapan Uji Bakar}

Uji bakar limbah B3 perlu perencanaan yang matang agar hasilnya dapat memenuhi ketentuan-ketentuan yang dipersyaratkan1,2. Oleh karena itu beberapa pekerjaan persiapan sebagai berikut perlu dilakukan.

\subsubsection{Sampling Limbah B3}

Sampling limbah B3 dilakukan untuk mendapatkan sampel limbah yang representatif untuk selanjutnya dilakukan analisis kimia. Sampling komposit dilakukan dari beberapa limbah secara cepat (grab) sebanyak kurang lebih 1 (satu) kilogram atau 1 (satu) liter sampel limbah. Pengumpulan dilakukan untuk minimum 4 (empat) sampel yang merupakan integrasi antara kedalaman dan luas area daripada limbah. Sampel komposit harus dicampur secara merata dan dibagi minimal dalam 3 (tiga) replikasi sebelum dibawa ke laboratorium ${ }^{9,10}$.

\subsubsection{Analisis Limbah B3}

Prosedur analisis dapat dibagi dalam tiga bagian1: a) karakteristik untuk penyimpanan, b) analisis proksimat terutama untuk nilai kalor, dan c) analisis spesifik, dalam hal ini untuk menentukan $\mathrm{POHC}$. Gambar 1 memberikan ilustrasi dalam pendekatan analisis ini.

Karakteristik sampel limbah, didefinisikan dalam mudah menyala, korosi, reaktif, dan beracun ${ }^{6,7,11}$. Testes ini dilakukan pada setiap sampel limbah kecuali jika cukup informasi dari hasil analisis teknis yang menyatakan bahwa limbah memenuhi setiap kriteria yang ditentukan tersebut. Informasi ini diperlukan dalam menetapkan prosedur untuk keselamatan penyimpanan, penanganan dan pembuangan limbah di lokasi pengolahan.

Analisis proksimat (proximate analysis) menghasilkan data terkait dengan bentuk fisik dan estimasi komposisi total daripada limbah. Analisis ini meliputi antara lain: penentuan kandungan air, padatan dan abu, komposisi elemen (karbon, nitrogen, sulfur, fosfor, fluorin, khlorin, bromine, yodium), nilai kalor limbah, dan viskositas. 


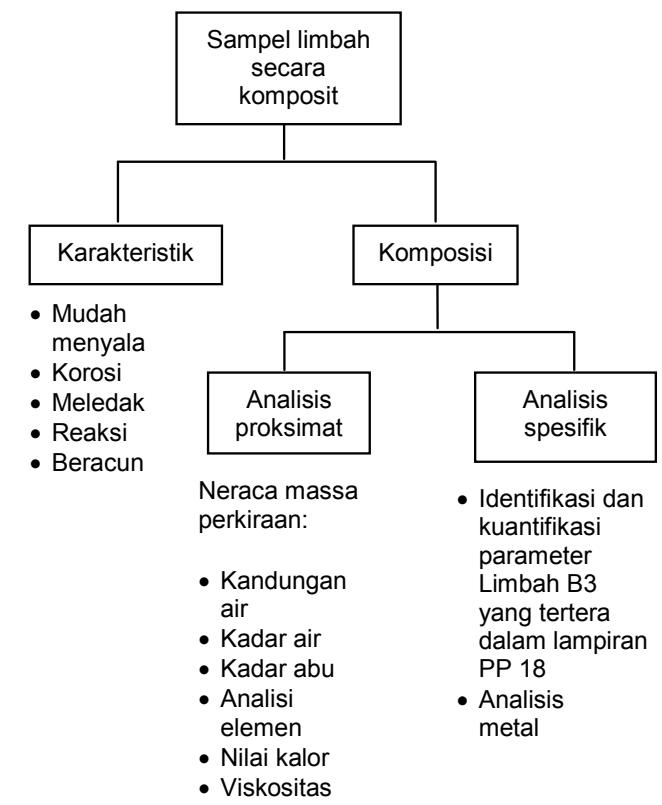

Gambar 1. Overview pendekatan analisis karakteristik limbah

Data komposisi elemen limbah memungkinkan adanya prediksi emisi dari produk pembakaran yang tinggi konsentrasinya (NOx, SOx, $\mathrm{HCl} / \mathrm{HF}$ dan halogen) selama insinerasi. Data-data ini juga memberikan informasi tentang kemungkinan adanya elemen limbah B3 seperti yang tertulis dalam Lampiran PP No.18/20096 (US EPA, 40 CFR Part 261, Appendix $\mathrm{VIII}^{7}$ ). Sebagai contohnya, jika bromin tidak terkandung dalam limbah, semua senyawa organobromine dari Appendix VIII akan dikeluarkan dari analisis spesifiknya.

Analisis spesifik (specific analysis) dalam karakterisasi limbah B3 akan memberikan konfirmasi keberadaannya secara kualitatif sehingga identifikasinya cukup berdasarkan keputusan profesional atau dari hasil analisis proksimat sehingga tidak perlu dilakukan analisis laboratorium secara rinci. Analisis spesifik tidak menyangkut screening setiap sampel limbah terhadap semua komponen berbahaya (hazardous). Keputusan awal dibuat terhadap senyawa atau tipe senyawa yang secara nyata terkandung. Untuk analisis organik spesifik, teknik separasi resolusi tinggi (fusedsilica capillarry gas chromatograph) dan teknik deteksi spektrometri yang tinggi (mass spectrometry) mungkin digunakan? Pendekatan ini untuk memberi keyakinan analisis secara kualitatif dan kuantitatif untuk berbagai tipe limbah dan proses kimia.

\subsubsection{Seleksi POHCs}

Kriteria seleksi POHC (biasanya satu sampai enam konstituen per limbah) meliputi: 1) prakiraan kesulitan degradasi termal dari berbagai konstituen organik berbahaya dalam limbah; dan 2) konsentrasi dari konstituen tersebut dalam limbah ${ }^{1,7}$.

Diantisipasi bahwa POHC yang ditentukan akan dinegosiasikan secara kasus per kasus untuk setiap aplikasi perijinan. Penting untuk dicatat bahwa tidak perlu senyawa dalam US EPA 40 CFR Part 261 Appendix $\mathrm{VIII}^{7}$ yang terkandung dalam limbah akan dianggap sebagai POHC. Tujuannya adalah untuk menyeleksi agar senyawa spesifik sesedikit mungkin sebagai indikator kinerja insinerator dengan demikian mudah dikelola dan murah biayanya.

Senyawa yang terseleksi harus memberikan uji bakar yang tepat dan cukup mewakili kinerja insinerator untuk memastikan bahwa insinerasi limbah dapat dilaksanakan dengan benar secara lingkungan. Kriteria ini memungkinkan adanya seleski konstituen POHC yang secara termal akan stabil dalam proses pembakarannya.

Walaupun demikian pada waktu yang sama perlu memastikan bahwa POHC terpilih yang terkandung dalam limbah konsentrasinya cukup tinggi dalam gas emisi di cerobong untuk bisa dideteksi dengan alat ukur. Hal ini sangat penting sebagai batasan untuk limbah yang akan diinsinerasi dengan bahan bakar yang jumlahnya banyak sehingga berpotensi mengencerkan $\mathrm{POHC}$ dalam emisi gas cerobong ${ }^{4,8}$. Konsentrasi yang rendah dari target $\mathrm{POHC}$ akan mempengaruhi limit 
deteksi alat ukur yang digunakan kecuali jika gas emisi yang disampel dinaikkan jumlahnya, yang berarti waktu sampling akan jauh lebih lama dengan laju sampling yang sudah tertentu dari alat sampling cerobong (biasanya sekitar 0,5 Liter per menit untuk $\mathrm{POHC})^{8}$.

Secara umum disarankan agar pemberi ijin menyeleksi POHC yang terkandung dalam limbah pada kadar $1000 \mathrm{mg} / \mathrm{kg}$ atau lebih atau menggunakan spike. Jika terpaksa harus memutuskan senyawa POHC yang secara termal stabil pada tingkat ratusan ppm, aplikasi ijin uji bakar harus memasukkan perhitungan dan data pendukung untuk mengindikasikan bahwa $0,01 \%$ laju alir massa dalam emisi gas akan dapat dideteksi oleh gas analyzer. Konsentrasi POHC $100 \mathrm{mg} / \mathrm{kg}$ secara praktis mungkin merepresentasikan batas bawah dalam penentuan DRE sebesar 99,99\% dan oleh karenanya memerlukan analisis sampling yang sangat luar bisa kecil limit deteksinya dan prosedur kontrol kualitas (quality control) yang sangat ketat sehingga pada gilirannya menaikkan biaya sampling dan analisis uji bakar.

\subsection{Sampling dan Analisis}

Penelitian ini mengambil kasus untuk limbah B3 padat dari jenis kain majun terkontaminasi, lumpur (sludge) dari instalasi pengolah limbah, dan limbah infeksius rumah sakit.

Limbah-limbah ini dilakukan sampling dan analisis untuk mengetahui karakterisasi sifat fisika dan kimia limbah. Sampling setiap jenis limbah dilakukan secara komposit dari 4 (empat) sub-sampel yang diambil mewakili tegakan dan luasan tumpukan limbah ${ }^{9,10 .}$

Parameter limbah B3 yang dianalisis diputuskan yaitu organik berkhlorinasi total, organik halida total dan organic phenol. Untuk organik berkhlorinasi selain total organik chlor juga dilakukan analisis untuk 1.1 Dichloro ethylene, 1.1.1 Trichloro ethylene, dan Tetrachloro ethylene. Selain itu, nilai kalor untuk masing-masing limbah juga dilakukan analisis. Metode analisis laboratorium yang digunakan terhadap 3 (tiga) jenis sampel limbah B3 tersebut dilakukan dengan metode baku9 seperti ditunjukkan dalam Tabel 1.

Tabel 1. Metode analisis limbah B3 yang digunakan untuk masing-masing parameter

\begin{tabular}{|l|l|}
\hline Paremeter & Metode \\
\hline 1.Total organic chlor & EPA SW 8468240 \\
\hline 2. Total organic phenol & EPA SW 8468240 \\
\hline 3. Total organic halide & APHA 5220 \\
\hline $\begin{array}{l}\text { 4. POHCs: } \\
\text { 1.1 Dichloroethylene }\end{array}$ & \\
EPA SW 8468270 \\
5. Tetrichloroethylene & \\
\hline
\end{tabular}

\section{HASIL ANALISIS DAN PEMBAHASAN}

\subsection{Hasil Analisis Laboratorium}

Hasil analisis laboratorium dari 3 jenis limbah B3 diberikan dalam Tabel 2, 3 dan 4 berikut.

Tabel 2. Hasil analisis laboratorium untuk sludge.

\begin{tabular}{|l|r|l|}
\hline Komponen & \multicolumn{1}{|l|}{ Nilai } & Unit \\
\hline 1. Total organic chlor & 1.94 & $\mathrm{mg} / \mathrm{kg}$ \\
\hline 2. Total organic phenol & $<0.66$ & $\mathrm{mg} / \mathrm{kg}$ \\
\hline 3. Total organic halide & 647 & $\mathrm{mg} / \mathrm{kg}$ \\
\hline 4. POHCs: & & \\
1.1. Dichloroethylene & 0.109 & \\
1.1.1 Trichloroethylene & 0.572 & $\mathrm{mg} / \mathrm{kg}$ \\
Tetrachloroethylene & 0.179 & \\
\hline Nilai kalor & 36 & $\mathrm{Kcal} / \mathrm{kg}$ \\
\hline
\end{tabular}


Tabel 3. Hasil analisis kain majun terkontaminasi

\begin{tabular}{|l|r|l|}
\hline Komponen & \multicolumn{1}{|c|}{ Nilai } & Unit \\
\hline 1. Total organic chlor & 4.30 & $\mathrm{mg} / \mathrm{kg}$ \\
\hline 2. Total organic phenol & $<0.66$ & $\mathrm{mg} / \mathrm{kg}$ \\
\hline 3. Total organic halide & 2000 & $\mathrm{mg} / \mathrm{kg}$ \\
\hline 4. POHCs: & & \\
1.1. Dichloroethylene & 4.035 & \\
1.1.1 Trichloroethylene & 0.082 & $\mathrm{mg} / \mathrm{kg}$ \\
Tetrachloroethylene & 0.179 & \\
\hline Nilai kalor & 2352 & $\mathrm{Kcal} / \mathrm{kg}$ \\
\hline
\end{tabular}

Tabel 4. Hasil analisis limbah infeksius

\begin{tabular}{|l|r|l|}
\hline Komponen & \multicolumn{1}{|l|}{ Nilai } & Unit \\
\hline 1. Total organic chlor & 2.67 & $\mathrm{mg} / \mathrm{kg}$ \\
\hline 2. Total organic phenol & $<0.66$ & $\mathrm{mg} / \mathrm{kg}$ \\
\hline 3. Total organic halide & 892 & $\mathrm{mg} / \mathrm{kg}$ \\
\hline 4. POHCs: & & \\
$\begin{array}{l}\text { 1.1. Dichloroethylene } \\
\text { 1.1.1 Trichloroethylene }\end{array}$ & 0.7242 & \\
Tetrachloroethylene & -1118 & $\mathrm{mg} / \mathrm{kg}$ \\
\hline Nilai kalor & 1896 & $\mathrm{Kcal} / \mathrm{kg}$ \\
\hline
\end{tabular}

\subsection{Pembahasan}

Nilai hasil analisis kimia dari 3 (tiga) jenis limbah berbeda-beda. Pembakaran limbah B3 dalam insinerator direncanakan dengan komposisi 50:30:20\% berturut-turut untuk lumpur WWTP:majun terkontaminasi: limbah klinis (lihat Tabel 5).

Tabel 5. Jumlah dan komposisi limbah yang rencana dibakar dalam insinerator per jam.

\begin{tabular}{|l|c|c|}
\hline Jenis limbah & $\begin{array}{l}\text { Komposisi } \\
\%\end{array}$ & $\begin{array}{l}\text { Berat } \\
\mathrm{Kg}\end{array}$ \\
\hline 1. Sludge WWTP & 50 & 150 \\
\hline 2. Majun terkontaminasi & 30 & 90 \\
\hline 3. Limbah infeksius & 20 & 60 \\
\hline Jumlah & 100 & 300 \\
\hline
\end{tabular}

Jumlah limbah yang dimasukkan dalam insinerator perjam sebesar $300 \mathrm{~kg}$. Dengan komposisi tersebut, maka nilai komponen kimia per kilogram berat campuran limbah dapat dihitung yang hasilnya disajikan dalam Tabel 6.

Tabel 6. Nilai kandungan kimia limbah campuran

\begin{tabular}{|l|r|l|}
\hline Komponen & \multicolumn{1}{|l|}{ Nilai } & Unit \\
\hline 1. Total organic chlor & 2,794 & $\mathrm{mg} / \mathrm{kg}$ \\
\hline 2. Total organic phenol & $<0,66$ & $\mathrm{mg} / \mathrm{kg}$ \\
\hline 3. Total organic halide & 1101,9 & $\mathrm{mg} / \mathrm{kg}$ \\
\hline 4. POHCs: & 1,411 & \\
1.1.Dichloroethylene & 0,311 & $\mathrm{mg} / \mathrm{kg}$ \\
1.1.1 Trichloroethylene & 0,166 & \\
Tetrachloroethylene & & \\
\hline 5. Nilai kalor & $1.102,8$ & $\mathrm{Kcal} / \mathrm{kg}$ \\
\hline
\end{tabular}

\subsubsection{Sampling untuk DRE POHC}

Umumnya dalam uji bakar, $\mathrm{POHC}$ yang tepat harus dipilih dan efisiensi penghancuran (destruction and removal efficiency/ DRE) untuk senyawa terpilih tersebut harus dibuktikan. Pemilihan POHC meliputi pemberian ranking senyawa organik yang terdaftar dalam Lampiran 3 PP 18/19996 atau dalam US EPA's regulations (40 CFR Part 261, Appendix VIII7), berdasarkan relatif kesulitannya terdestruksi atau terbakar.

Salah satu metode yang biasa digunakan dalam melakukan ranking senyawa organik berbahaya sebagai $\mathrm{POHC}$ adalah panas indek pembakaran (heat of combustion index). Metode panas indek pembakaran berdasarkan teori ekulibrium yang menyatakan bahwa fokus utama dalam mengevaluasi sulitnya tingkat penghancuran untuk suatu parameter adalah jumlah energi yang yang diperlukan dalam melakukan pembakaran yang sempurna12. Panas indek pembakaran mengasumsikan bahwa senyawa yang memiliki nilai panas pembakaran yang rendah akan kurang mampu menimbulkan pembakaran sempurna dibandingkan dengan senyawa yang memiliki nilai panas pembakaran yang tinggi.

POHC yang mewakili dalam desain uji bakar diindentifikasi berdasarkan hasil 
analisis laboratorium limbah yang dilakukan oleh pemohon ijin, seperti terlihat dalam Tabel 6. Untuk mengetahui kemampuan bakar adalah berdasarkan indikator kemampuan terbakar yang merupakan fungsi nilai pembakaran (heating value) dan konsentrasi, seperti dinyatakan dalam hubungan berikut ${ }^{12}$ :

$$
I=\stackrel{a}{C^{+}}
$$

dimana;

$\mathrm{I}=$ indek kemampuan terbakar (tambah tinggi nilai I tambah sulit terbakar), tak berdimensi;

$\mathrm{a}=$ konstanta konversi unit, $100 \mathrm{kcal} / \mathrm{gram}$;

$\mathrm{C}=$ konsentrasi;

$\mathrm{H}=$ nilai pembakaran (heating value), kcal/ gram.

Dalam analisis kimia limbah B3 yang diajukan untuk perijinan, terdapat 3 (tiga) senyawa POHC seperti terlihat dalam Tabel 6. Dari daftar senyawa terhadap nilai pembakaran ${ }^{6,7}$, maka dapat diketahui masing-masing nilai pembakaran $(\mathrm{H})$ dari 3 (tiga) senyawa tersebut. Dengan mengetahui konsentrasi hasil analisis kimia (Tabel 6), maka nilai indek kemampuan terbakar (I) dapat dihitung seperti disajikan dalam Tabel 7 .

Kemungkinan kandidat $\mathrm{POHC}$ dari

Tabel 7. Konsentrasi, nilai kalor dan nilai kemampuan terbakar $\mathrm{POHC}$ dari limbah B3

\begin{tabular}{|l|c|c|l|}
\hline \multicolumn{1}{|c|}{ Senyawa } & $\begin{array}{c}\mathrm{C} \\
\mathrm{ppm}\end{array}$ & $\begin{array}{c}\mathrm{H} \\
\mathrm{kcal} /\end{array}$ & \multicolumn{1}{|c|}{$\mathrm{I}$} \\
\hline 1.1.Dichloroethylene & 1,411 & 2,70 & 38,45 \\
\hline 1.1.1 Trichloroethylene & 0,311 & 1,74 & 7,78 \\
\hline Tetrachloroethylene & 0,166 & 1,19 & 84,20 \\
\hline
\end{tabular}

limbah B3 ini untuk mewakili uji bakar adalah Tetrachloroethylene karena menghasilkan indek kemampuan terbakar (I) yang tertinggi, yaitu 84,20 . Walaupun mempunyai konsentrasi yang terendah dari ketiganya, nilai bakar Tetrachloroethylene sangat rendah artinya sulit terbakar.

Untuk penentuan DRE, konsentrasi Tetrachloroethylene yang masuk ke insinerator harus ditentukan jumlahnya dengan memperhitungan batas deteksi gas chromatographic - mass spectra ${ }^{13}$.

Sampling DRE harus dilaksanakan dengan rangkaian sampling sesuai metode baku pada laju alir sampling rendah ${ }^{8}$. Laju alir sampling sekitar 0,5 liter per menit selama 40 menit setiap pasang tabung penyerap (trap) dengan ulangan tiga kali13. Sebagai kontrol kualitas (QC), blanko sampel (sample blank) yang terdiri dari blanko laboratorium (lab blank), blanko perjalanan (trip blank) blanko lapangan (field blank) dengan jumlah secukupnya harus dilakukan ${ }^{8,13}$.

Maksud sampel blanko adalah untuk mengoreksi hasil sampling yang kemungkinan terjadi kontaminasi atau hal-hal lain yang tidak diinginkan terjadi selain hasil sampling. Nilai sampel blanko adalah sampel acak (random samples) yang bervariasi akibat kegiatan persiapan, penanganan dan analisis. Dengan asumsi demikian maka nilai blanko dapat diestimasi secara statistik. Estimasi terbaik nilai blanko untuk sampel tertentu adalah nilai rata-rata dari nilai blanko yang ada ${ }^{9}$.

DRE akan dihitung dengan rumus sebagai berikut ${ }^{3}$ :

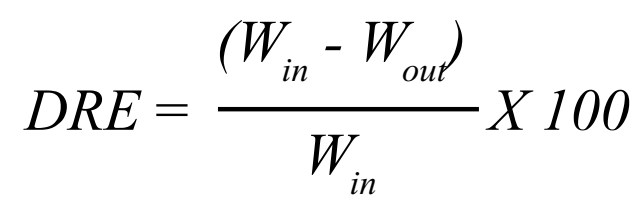

DRE : Destruction and Removal Efficiency (\%)

Win : PERC masuk ke insinerator $(\mathrm{kg} / \mathrm{jam})$ Wout : Laju emisi PERC diukur oleh VOST di cerobong $(\mathrm{kg} / \mathrm{jam})$

Dari hasil perhitungan DRE POHC Tetrachloroethylene nantinya, nilai untuk semua tiga ulangan harus diatas $99,99 \%$, 12 . 


\subsubsection{Polutan lain: Partikulat, logam berat dan $\mathrm{HCl}$.}

Potensi limbah B3 yang diajukan untuk dibakar di insinerator diperkirakan mengemisikan partikulat dan kemungkinan besar logam-logam berat. Walaupun sistem insinerator dilengkapi dengan alat kontrol partikulat berbentuk scrubber, emisi partikulat dan logam berat tetap akan terjadi. Oleh karena itu, uji bakar ini harus dilengkapi dengan sampling partikulat dan logam berat $14,15,16$.

Metode menentukan DRE untuk logam maupun $\mathrm{HCl}$ sama dengan cara penentuan DRE untuk POHC, yaitu menentukan besarnya masukan logam atau $\mathrm{HCl}$ yang akan dibakar dalam insinerator sedemikian rupa sehingga dapat dideteksi dengan alat ukur dari hasil sampling cerobong. Jadi, umumnya dilakukan penambahan spike polutan sehingga polutan yang disampel akan bisa dideteksi setelah memperhitungkan pengenceran yang terjadi. Selain pengukuran DRE, pengukuran emisi partikulat, logam berat, $\mathrm{HCl}^{14,15,16}$ tanpa adanya spike bisa juga dilakukan dan hasilnya dibandingkan dengan nilai baku mutu, sesuai lampiran Keputusan Kepala BAPEDAL No. Kep. 03 Tahun 1995³.

Metode sampling isokinetik yang digunakan untuk partikulat ${ }^{14,15}$ harus diawali dengan penentuan lokasi lobang sampling dan titik-titik sampling ${ }^{15,17}$, penentuan kecepatan alir gas ${ }^{15,18}$, penentuan berat molekul gas emisi ${ }^{15,19}$, dan pengukuran kadar air gas di cerobong ${ }^{15,20}$. Untuk sampling logam berat harus menggunakan Method 29 US-EPA ${ }^{16}$ karena metode sampling logam berat belum ditetapkan oleh Pemerintah Indonesia. Jenis-jenis logam berat meliputi antara lain arsen (As), Thallium ( $\mathrm{Tl}$ ), cadmium $(\mathrm{Cd})$, chromium $(\mathrm{Cr})$, lead $(\mathrm{Pb})$ and mercury $(\mathrm{Hg})$.

Prinsip kerja dari alat sampling partikulat dan logam berat yaitu menarik gas emisi dari cerobong ke pipa sampling (probe) secara isokinetik. Sampel yang berupa partikulat (padat) akan terkumpul dalam pipa sampling (probe) dan menempel pada filter yang dijaga suhunya sekitar $120^{\circ} \mathrm{C}$. Emisi yang berupa gas diserap dalam larutan asam hidrogen peroksida (yang akan dianalisis semua logam berat termasuk $\mathrm{Hg}$ ) dan larutan asam potasium permanganat (yang akan dianalisis hanya $\mathrm{Hg})^{21}$. Partikulat total yang terkumpul dalam pipa sampling dan filter dikirim ke laboratorium untuk ditimbang beratnya dan logam berat yang ada di dalamnya termasuk yang diserap dalam cairan penyerap di impinger dianalisis kadar logam beratnya dengan Atomic Absorption Analyzer.

Potensi limbah B3 yang diajukan untuk dibakar di insinerator diperkirakan juga mengemisikan hidrogen khlorida $(\mathrm{HCl})$. Oleh karena itu, uji bakar ini harus dilengkapi dengan sampling $\mathrm{HCl}^{15}$.

Prinsip kerja dari alat sampling $\mathrm{HCl}$ adalah menarik emisi gas dari cerobong kemudian melewati pipa sampling dan filter yang dipanaskan dan akhirnya masuk ke larutan asam sulfat encer dalam impinger yang akan menyerap hidrogen khlorida $(\mathrm{HCl})$.

Jadi, dalam kasus limbah B3 yang dievaluasi dalam penelitian ini, kegiatan sampling yang akan dipersiapkan meliputi:

- DRE untuk POHC yang diwakili oleh Tetrachloroethylene.

- $\quad$ Partikulat dan logam berat.

- $\mathrm{HCl}$.

- Gas-gas lainnya: $\mathrm{O}_{2}, \mathrm{CO}$, kadar air, aliran emisi.

\section{EVALUASI DAN SARAN}

\subsection{Evaluasi}

Analisis limbah B3 padat untuk umpan insinerator dimaksudkan untuk mengetahui limbah apa atau dari mana penyebab munculnya bahan pencemar ketika diukur emisinya dalam uji bakar (trial burn test). Untuk itu diperlukan parameter uji bakar yang terencana dengan baik secara rinci, apa yang akan diukur dan bagaimana cara 
mengukurnya. Selain itu, data-data apa saja yang harus dicatat agar evaluasi hasil uji bakar dapat dilakukan dengan baik.

Dari data analisis laboratorium, limbah yang mengandung Total organic chlor dan organic Halide (TOX) terbesar adalah limbah kain majun terkontaminasi, yaitu masingmasing 4,30 dan $2000 \mathrm{mg} / \mathrm{kg}$. Dengan nilai terbesar khlor total hanya $4,3 \mathrm{mg} / \mathrm{kg}$, potensi pembentukan dioksin dianggap kecil sehingga tidak disarankan untuk dilakukan pengukuran gas emisi.

Perlu diketahui bahwa sumber dioksin adalah berasal dari 2 kelompok proses industri: proses kimia dan proses thermal. Kondisi yang diindentifikasi menghasilkan dioxin dalam proses thermal adalah terdapat kandungan senyawa khlorin atau yang mengandung khlorin, suhu dalam sistem antara $200-400^{\circ} \mathrm{C}$, tipe dari alat kontrol polusi yang beroperasi pada suhu 200$400^{\circ} \mathrm{C}$. Berdasarkan kriteria diatas, berikut ini urutan proses dari sisi besarnya potensi terbentuknya dioxin:

- Proses yang melibatkan chlorophenols dan turunannya.

- Proses yang melibatkan chlorobenzenes, subsitusi senyawa chloroaromatic dan turunannya.

- Synthesis senyawa chlorinated aliphatic.

- Proses dimana khlorin adalah bagian molekul dalam intermediate stage tetapi bukan produk akhir.

- Proses melibatkan khlorin kimia anorganik..

- Proses melibatkan katalis atau solven yang mengandung khlorin.

Mengingat kandungan calon dioksin (dioxin precursors) relatif kecil dan juga mempertimbangkan segi teknis operasional dan ekonomis maka diputuskan tidak dilakukan pengukuran dioksin.

Pengukuran DRE hanya difokuskan pada POHC yang diwakili oleh Tetrachloroethylene yang mempunyai indek bakarnya yang sangat rendah sehingga diharapkan dapat mewakili semua $\mathrm{POHC}$ yang mungkin terkandung dalam limbah B3 yang dibakar.

Selain itu, limbah yang dibakar kebanyakan berbentuk padat sehingga potensi keluarnya partikulat dan logam berat sangat mungkin. Oleh karenanya sampling partikulat dan logam berat perlu dilakukan apakah dalam skenario DRE atau dalam hubungannya dengan pemenuhan baku mutu emisi ${ }^{3}$.

Polutan lain yang diperkirakan akan teremisikan dari insinerator adalah $\mathrm{HCl}$ dan oleh karenanya perlu dilakukan pengukuran.

\subsection{Saran}

Perhatian harus diberikan pada pengumpanan ke insinerator yang dilakukan secara manual. Komposisi jumlah limbah yang dibakar, bahan bakar dan udara pembakarannya harus benar-benar presisi agar tercapai pembakaran dengan suhu yang diinginkan. Kontrol bahan umpan tersebut secara otomatik sangat disarankan.

Setiap limbah yang akan dibakar sebaiknya dilakukan pengambilan sampel dan analisis laboratorium secara periodik untuk parameter calon dioksin (dioxin precursor), antara lain PCBs, Total Organic Chlor, dan kadar logam-logam berat sesuai dengan persyaratan ijin pembakaran di insinerator. Jika nilainya tinggi maka tidak digunakan atau penggunaannya dikurangi jumlahnya. Oleh karena itu, laboratorium sebaiknya disediakan atau bekerjasama dengan laboratorium yang terakreditasi untuk analisis sampel tersebut.

Pengoperasian insinerator harus benarbenar dijaga suhunya $\left(1000^{\circ} \mathrm{C}\right)$ terutama agar limbah B3 yang dimasukkan dalam incinerator terbakar dengan sempurna. Pembakaran sempurna harus dilakukan dengan memonitor kadar $\mathrm{CO}$ dan $\mathrm{CO}_{2}$ emisi di cerobong atau setelah ruang tungku terakhir dan diindikasikan dengan nilai efisiensi pembakarannya yang dapat dihitung dengan rumus ${ }^{3} \mathrm{sbb}$ : 


$$
C E=\frac{\mathrm{CO}_{2}}{C \mathrm{O}_{2}+\left(\mathrm{CO} \times 10^{-4}\right)} \times 100
$$

dimana:

CE : Efisensi pembakaran, \%

$\mathrm{CO}_{2}$ : Konsentrasi $\mathrm{CO}^{2}, \%$

$\mathrm{CO}$ : Konsentrasi $\mathrm{CO}, \mathrm{ppm}$.

Dengan demikian alat pemantuan kadar $\mathrm{CO}$ dan $\mathrm{CO}^{2}$ di emisi (flue gas) sebaiknya dipasang.

Selain itu, pemantuan parameter emisi lain sesuai dengan Kep Ka-Bapedal No. $3 / 1995$, misalnya $\mathrm{HCl}$, beberapa metal, serta parameter-parameter lain, harus dilakukan secara rutin di cerobong.

Limbah-limbah padat dan cair yang diterima dari pihak lain dan diolah di lokasi pabrik harus benar-benar ditangani dengan prosedur yang benar. Semua data penerimaan harus tercatat dalam manifest yang bisa sewaktu-waktu dilakukan pengecekan.

Dalam kaitannya dengan operasi incinerator, waktu pengoperasian sebaiknya selama mungkin (minimal 7 hari) karena untuk mengurangi potensi suhu yang rendah ketika start-up dan cooling down, dimana potensi terbentuknya dioksin sangat besar. Seperti data yang diberikan bahwa untuk mencapai suhu $90^{\circ} \mathrm{C}$ ketika start up diperlukan waktu 10-11 jam dan demikian juga tentunya ketika shut-down (cooling down). Oleh karenanya dari sisi lingkungan dan biaya maka waktu operasi yang lama akan lebih baik.

Alat kontrol polusi scrubber harap dihitung efisiensinya dari data pengukuran apakah memang mampu untuk melakukan penangkapan polutan sehingga aman untuk diemisikan melalui cerobong.

\section{UCAPAN TERIMA KASIH}

Penulis mengucapkan terima kasih kepada PT. Tenang Jaya Sejahtera yang telah menyampaikan data-data analisis limbah B3 yang direncanakan akan dibakar dalam insinerator dalam kerangka TBT dan selanjutnya perijinan. Penulis juga mengucapkan terima kasih kepada Sys Lab yang telah melakukan analisis kimia sesuai dengan metode baku.

\section{DAFTAR PUSTAKA}

1. Brunner, C.R., 1989, Handbook of Hazardous Waste Incineration, TAB BOOKS Inc, US, 1st Ed, 388 hal.

2. Peraturan Menteri Lingkungan Hidup Nomor 18 Tahun 2009 tentang Tata Cara Perizinan Pengelolaan Limbah Bahan Berbahaya dan Beracun.

3. Keputusan Kepala Badan Pengendalian Dampak Lingkungan No. Kep-03/ BAPEDAL/09/1995, tentang Persyaratan Teknis Pengolahan Limbah Bahan Berbahaya dan Beracun.

4. Kardono, 2012, Pengolahan Limbah Secara Termal, Paper disampaikan dalam rapat di $\mathrm{KLH}$.

5. Kardono, 2002, Destruction Removal Efficiency (DRE) of Waste Derived Synthetic Fuel through Cement Kiln, dalam Jurnal IImu Pengetahuan, Teknologi dan Budaya Al Azhar Indonesia, Vol.: 1, No.: 2, Desember 2002, ISSN 1412-8659

6. Peraturan Pemerintah Republik Indonesia, Nomor 18 Tahun 1999 tentang Pengelolaan Limbah Bahan Berbahaya dan Beracun.

7. US EPA's regulations (40 CFR Part 261, Appendix VIII).

8. US-EPA Method 30 - Volatile Organic Sampling Train. 
9. US EPA's publication SW-846, Test Methods for Evaluating Solid Waste, Physical/ Chemical Methods.

10. Kardono, 2008, Persyaratan Laboratorium Lingkungan dan Kondisinya di Indonesia, Jurnal Teknologi Lingkungan, Vol.: 9 No.: 2 Hal. :109 - 118, Jakarta, Mei 2008, ISSN 1441-318.

11. Manahan, S.E, 1984, Environmental Chemistry, PWS Publishers, 4th Ed, 612 hal.

12. US EPA's regulations (40 CFR 264 Subpart $\mathrm{O}$ - Incinerators.

13. Kardono, 2006, Measurement of Selected Principal Organic Hazardous Constituent (POHC) in Cement Kiln, Jurnal Teknologi Lingkungan, Edisi Khusus, Hal. :44-50, Jakarta, Juli 2006, ISSN 1441-318x. .

14. US-EPA Method 5 -- Determination of Particulate Emission from Stationary Sources
15. Keputusan Kepala Badan Pengendalian Dampak Lingkungan No. Kep-205/ BAPEDAL/09/1995, tentang Pedoman Teknis Pengendalian Pencemaran Udara, Lampiran 2.

16. US-EPA Method 29 -- Determination of Metals Emissions from Stationary Sources (As, Cd, Cr, Pb, Hg, Tl)

17. US-EPAMethod 1-Sample and velocity traverses for stationary sources.

18. US-EPA Method 2 -- Determination of Stack Gas Velocity and Volumetric Flow Rate (Type-s Pitot Tube)

19. US-EPA Method 3A -- Determination of Oxygen and Carbon Dioxide Concentrations in Emissions From Stationary Sources (Instrumental Analyzer Procedure)

20. US-EPA Method 4 -- Determination of Moisture Content in Stack Gases

21. Kardono, Application of US-EPAMethod 29: Sampling Metals Emissions from Stationary Source Jurnal Teknologi Lingkungan, Vol.: 8, No.: 2, Hal. :105112, Jakarta, Mei 2007, ISSN 1441318. 